Voix et Images

voixetimages

\title{
Entrevue avec Naïm Kattan
}

Jacques Allard

Volume 11, numéro 1, automne 1985

\section{Naïm Kattan}

URI : https://id.erudit.org/iderudit/200534ar

DOI : https://doi.org/10.7202/200534ar

Aller au sommaire du numéro

\section{Éditeur(s)}

Université du Québec à Montréal

\section{ISSN}

0318-9201 (imprimé)

1705-933X (numérique)

Découvrir la revue

Citer ce document

Allard, J. (1985). Entrevue avec Naïm Kattan. Voix et Images, 11(1), 10-32.

https://doi.org/10.7202/200534ar d'utilisation que vous pouvez consulter en ligne.

https://apropos.erudit.org/fr/usagers/politique-dutilisation/ 


\title{
Entrevue avec Naïm Kattan
}

\author{
par Jacques Allard, Université du Québec à Montréal
}

\section{Bagdad}

V. \& I. - Il y a dans ton ouvre un mot clé qui apparaît dès le Réel et le théâtral, que je retrouve dans le Désir et le pouvoir, la Mémoire et la promesse et Adieu Babylone, je viens de le dire, c'est le mot promesse. Alors partons de là : à quoi es-tu promis quand tu nais à Bagdad en 1928, je veux dire avant même d'affirmer vers 12 ou 13 ans une volonté d'écrivain?

N. Kattan - Je vais répondre en contant une anecdote qui se rapporte à ma naissance. Il faut d'abord la situer dans le contexte du Moyen-Orient et de Bagdad, et d'une communauté juive, dans un pays qui était à l'époque presqu'à quatre-vingt quinze pour cent illettré et qui était très archaïque. Quand je suis né, le quatrième de cinq enfants, (j'avais un frère aîné, deux soeurs) on attendait un deuxième garçon, parce que c'était très important d'avoir des garçons dans ce pays-là. Et j'avais une grand-mère qui à l'époque vivait avec nous, une grand-mère maternelle, et qui attendait ma naissance avec une impatience confiante parce qu'elle avait vu en rêve que mon grandpère, mort, allait revenir à la vie. Ce serait donc un garçon! Quand je suis né, ma mère a eu des difficultés mais ce fut fait par une sage-femme, à la maison, et ma mère fut sauvée. Et j'étais un garçon en pleine santé. Il faut toujours remettre ça en contexte: il y avait alors beaucoup de femmes qui mouraient lors de l'accouchement et, aussi, beaucoup d'enfants. Ma grand-mère me racontait toujours l'histoire de ma naissance en disant qu'il était tard dans la nuit, deux heures du matin, peut-être deux heures et demie, et que quand je suis venu au monde, une lumière avait soudain rempli la salle de ma naissance. C'était la mythologie... Je parle de cette grand-mère parce qu'elle a été très importante pour moi. J'étais le quatrième et ni mon père ni ma mère n'avaient le temps d'avoir de l'attention pour moi: il y avait d'autres enfants, ma grandmère m'a donc adopté et a dit que j'étais le plus beau, le plus intelligent de tous et que je ressemblais à son second fils, parti à seize ans à l'aventure, à dos d'âne sans le sou et qui avait fait fortune, était devenu millionnaire et aidait la famille. Elle disait que mon destin était déjà inscrit: je n'étais pas le premier né mais j'allais avoir un grand destin comme mon oncle Menashi dont je parle d'ailleurs dans Adieu Babylone. Donc, toute mon enfance j'ai été nourri par cette idée que j'avais un grand destin, celui de quelqu'un qui allait partir comme mon oncle et qui allait faire fortune quelque part... il faut aussi que je dise que ma famille était pauvre, quoique la famille de ma grand-mère avait été très fortunée et surtout on y retrouvait des rabbins. C'était plus important d'avoir des rabbins dans la famille que d'avoir de l'argent parce que là était la grande noblesse. Il y avait donc de la noblesse dans ma famille, et du côté maternel et du côté paternel, mais des deux côtés c'étaient des familles qui avaient perdu tout argent. Mon père était un tout petit employé au bureau de poste et n'avait pas pu, après le règne des Turcs, s'acclimater et devenir un haut fonctionnaire. Donc, j'ai été élevé par la famille de ma mère. Dans ce contexte de passé et d'avenir tout aussi grandiose l'un que l'autre, je vivais dans une sorte de pauvreté où il y avait beaucoup d'amour, aussi. 
V. \& I. - Est-ce que tu pourrais préciser ce que veut dire cette noblesse dans la perspective de la culture juive et dans un milieu arabe?

N. Kattan - D'abord, -dans un milieu arabe, être Juif, c'était pas être persécuté ou maltraité, mais être dans un certain sens admiré et parfois envié ou jalousé, parce qu'il y avait une sorte de concurrence entre tribus. Les Musulmans voyaient les Juifs comme des gens du Livre qu'ils ne voulaient pas convertir, ce qui est très important. Ils respectaient leur religion mais en même temps les Juifs étaient lettrés dans un pays à quatre-vingt quinze pour cent illettré. Les Juifs étaient lettrés parce qu'il y avait une obligation pour eux de prier. Et ils ne pouvaient pas prier sans lire. On ne peut pas prier en hébreu par cour. Il faut pouvoir lire. Même un rabbin, quand il lit une prière, doit sortir son livre; il ne doit pas la lire par cœur, il doit la lire dans le texte. C'est l'écrit qui fait loi, pas l'oral. L'oral est très important mais la loi est écrite. Tout père juif voulait au moins un fils pour que ce fils apprenne le cadish, la prière des morts, pour qu'après sa mort il y ait quelqu'un qui lise le cadish... pour que son destin sur terre soit accompli. Alors j'ai vécu ainsi: il y avait ce sentiment de confiance en moi au départ mais aussi la conscience que mon destin ne pouvait être accompli que par moi. J'avais les instruments pour l'accomplir mais rien n'était donné au départ.

V. \& I. - Et à propos du nom? Je sais que tu accordes une grande importance au nom.

N. Kattan - Je vais donner la signification de mes deux noms, en hébreu et en arabe. En hébreu, le nom de Kattan veut dire petit. C'est une description, comme dans toutes les langues il y a des noms de gens petits. Mais Naïm veut dire charmant, agréable. Alors il y avait cette double signification. Du côté arabe le mot Naïm est encore plus élogieux. C'est paradisiaque. C'est la grande fortune d'être dans un climat de paradis. Et Kattan veut dire cotonnier.

V. \& I. - Est-ce que c'était particulièrement voulu par tes parents de te donner un prénom qui ait aussi un sens en arabe?

N. Kattan - Oui ils voulaient que j'aie un nom double. Ils ont donné à mon frère un nom tout à fait occidental, Albert, à mes deux sœurs des noms tout autant arabes, ma deuxième sœur s'appelait Violette - et ça je reviendrai à l'importance de l'Occident déjà à ce moment-là - mais à moi on m'a donné un nom qui était très commun à l'époque et qui était à la fois arabe et juif.

V. \& I. - Ça m'amène au fond à un autre terme fondamental dans ton œuvre, c'est celui de l'échange. Si la promesse est fondatrice, l'échange est vital. L'échange, le commerce au sens le plus noble, le plus grand du terme, le rapport aux autres.

N. Kattan - Je crois que, là, c'est très fondamental pour moi cette question. Quand j'étais enfant l'une des premières préoccupations que j'ai eues, un des premiers mouvements de ma vie, c'était de pouvoir m'exprimer, de pouvoir être écrivain. C'était mon rêve d'enfant.

V. \& I. - $\AA$ quel âge? Est-ce que c'est avant dix ans?

N. Kattan - Avant dix ans, je commençais à lire et mon rêve c'était d'être un écrivain. Je ne peux pas m'imaginer sans avoir rêvé à ça, de pouvoir 
écrire. C'était mon grand rêve. Et en même temps, si possible, ou si c'était pas faisable, c'était d'être un grand commerçant, comme mon oncle, et traverser le monde et faire fortune dans le monde. Mais mon premier rêve, c'était d'écrire.

V. \& I. - Est-ce que c'était parce que la Bible était déjà très présente, est-ce que le texte se trouvait sacralisé dès ton enfance?

N. Kattan - Peut-être maintenant que je dirais ça mais il y a autre chose. Je crois qu'à l'époque, si je revois ma vie, c'était une vie très limitée. Il faut imaginer Bagdad dans les années quarante et même trente jusqu'à mon arrivée à Paris, je n'ai jamais vu de théâtre, jamais écouté de la musique occidentale, jamais parlé véritablement à une femme, donc c'était là une vie très serrée, très limitée et très archaïque, et j’en souffrais comme enfant. Pour moi, la seule manière de m'en sortir, c'était de lire. Et quand je ne pouvais pas avoir les livres, je les copiais, je les recopiais, je les importais _-je suis devenu importateur de livres français pendant la guerre et après la guerre simplement pour pouvoir les lire - «arracher» un livre c'était pour moi quelque chose de très important. La lecture était pour moi l'issue et c'était l'Occident, déjà. Mais aller vers l'Occident pour moi à l'époque c'était une manière encore plus importante d'être de chez-moi, d'être Irakien. Mais qu'est-ce que ça voulait dire être Irakien? J'allais à une école juive à Bagdad, l'Alliance israélite universelle, qui enseignait le français, l'anglais, l'hébreu et l'arabe, mais la langue principale était l'arabe, c'était la langue dont on était fier, dont j'étais fier moi-même, particulièrement. Tous mes copains, sauf un, se destinaient à une carrière médicale, scientifique, etc., moi je me destinais à la carrière des lettres. J'allais donc dans une école juive, je ne connaissais pas de Musulmans, et j'avais un rapport avec l'Europe par la lecture et soudain je me suis rendu compte que pour moi ce qui comptait c'était écrire en arabe. C'était de ma langue maternelle que j'étais fier. J'étais premier en classe en arabe et c'était ma plus grande fierté d'être le meilleur en arabe. J'ai commencé à écrire, d'ailleurs, à partir de l'école de l'Alliance, à partir de mes années de secondaire vers douze ou treize ans. J'ai écrit ma première nouvelle à treize ans et je l'ai publiée à quatorze. Après l'école élémentaire, mes deux dernières années de l'école secondaire, j'avais le choix d'aller à une autre école juive pour faire les sciences, il n'y avait pas d'écoles juives pour l'option lettres, alors je suis allé d'abord travailler, j'étais obligé de travailler, je voulais travailler pour être indépendant, j'ai commencé à travailler à treize ou quatorze ans, et je suis allé à l'école secondaire musulmane, ce que je raconte d'ailleurs dans Adieu Babylone, dans cette école où il n'y avait que moi et un autre étudiant juif qui avait les mêmes intérêts que moi pour la littérature. Et c'était une option fondamentale d'aller apprendre la culture arabe. Ce que cela voulait dire aller dans une école musulmane étudier en arabe c'était d'apprendre le Coran par cœur, la poésie pré-islamique, être au courant de tout ce qui est. le plus musulman et le plus arabe. Et pour moi c'était une grande fierté de le faire. Et à partir de ce moment-là, je quittais indirectement la communauté juive pour aller vers la communauté musulmane. J'ai envoyé des articles à des revues, à des journaux, et je commençais à fréquenter des Musulmans qui avaient les mêmes intérêts que moi. 
V. \& I. - Ce qui est frappant, c'est que rion seulement tu choisis et valorises le développement de ta culture arabe mais tu vas aussi vers la langue et la littérature française au moment où tu vis dans un pays dominé par les Britanniques. Pourquoi alors ce troisième choix tout en ne refusant pas tout à fait la langue anglaise non plus?

N. Kattan - J'avais le choix entre le français et l'anglais comme deuxième langue, c'était à parité. J'apprenais autant l'anglais que le français et j'ai choisi le français parce que pour moi l'Occident libérateur était francophone. La France était le pays qui me libérait. Quand je commençais à lire les Français, je trouvais tout. Je cherchais évidemment, ce que je cherchais je le trouvais dans la littérature française. Tout ce que je voulais de libérateur, je le trouvais dans cette littérature-là.

V. \& I. - Quel est ton premier souvenir de la littérature française? Est-ce que c'est Jean Christophe?

N. Kattan - Le premier grand livre pour moi, enfin j'ai lu d'autres, j'ai lu Alphonse Daudet, j'ai lu d'autres livres mais qui ne m'ont pas marqué: les Trois mousquetaires, Victor Hugo, que j'ai lu en arabe, j'ai lu tous ces livreslà, mais le livre qui m'a le plus marqué à l'époque c'était Jean Christophe et c'était, juste après, les Nourritures terrestres. C'était les deux livres d'appel de l'Occident, vers la libération, un appel à quitter le pays, quitter son milieu et aller ailleurs. Les Nourritures terrestres c'était un appel à quitter la famille, le milieu. Je ne voyais pas la révolte, moi, je voyais uniquement l'appel au large, l'appel à partir, à sortir, toutes les libérations consistaient à être ailleurs. C'est à ce moment-là que j'ai senti que je ne pouvais pas, je ne pouvvais plus rester sur place. J'étais déjà ailleurs dans ma culture. J'étais de langue arabe, j'étais très enraciné dans cette culture-là mais je commençais à traduire des oeuvres occidentales, des poèmes: j'ai traduit Aragon, Pierre Emmanuel, tout ce qui était poème de la résistance - il faut dire qu'à l'époque la France était encore occupée - tout ce qui était résistance pour moi, la libération de la France, c'était ma libération à moi. J'ai ressenti quand Paris était libéré - je me souviens parfaitement de l'instant où j'ai appris ça par la radio, je marchais dans la rue et j'ai dit: Paris s'est libéré, $j$ 'y vais. Paris s'était libéré pour moi!

V. \& I. - Mais de quoi voulais-tu te libérer à cette époque?

N. Kattan - Me libérer de l'archaïsme... Il n'y avait pas de femmes. Quand je lisais dans Jean Christophe des histoires d'amours entre adolescents, c'était quelque chose d'inouï, c'était ça la libération. Pas seulement de lui faire l'amour à la femme, mais de lui parler, de la voir de près, de lui parler, simplement. C'était ça la libération. C'était, dans Jean Christophe encore, ne pas simplement parler de musique mais l'écouter, pouvoir écouter cette musique dont il parlait. Qu'est-ce que c'était cette musique? Et ensuite qu'estce que c'était le paysage dont il parlait, le printemps? Il y avait beaucoup de choses dont j'étais privé. Je vivais dans un pays de désert, un climat très dur, mais aussi un climat moralement, pas seulement moralement mais matériellement démuni. Je n'avais que des livres pour rêver de cette vie complète où il $\mathrm{y}$ avait à la fois art, musique, vie sociale et femmes. 
V. \& I. - Revenons maintenant à ta première publication: pourrais-tu en résumer l'histoire?

N. Kattan - Ma première nouvelle avait pour titre: Un homme bizarre. Je viens de la relire après peut-être quarante ans: elle est très amusante pour moi, mais aussi presque prémonitoire. C'est l'histoire d'un garçon qui est le narrateur et à qui on dit: Regarde cet homme-là, c'est un fou. Lui est très attiré par ce fou, il va chez lui, il voit que c'est un écrivain qui est aussi un peintre. Cet écrivain-peintre ne vit que d'expédients, pour pouvoir continuer à écrire. Et il écrit et il peint sous une impulsion irrépressible comme dans la folie. On comprend ainsi que la nouvelle soit dédiée, en exergue, à ceux qui se brûlent pour éclairer, c'était puéril mais aussi prémonitoire puisqu'elle indiquait déjà, pour moi, le rapport entre l'artiste et la société, les minorités et les majorités. La conclusion de la nouvelle est qu'un fou parmi les sages, c'est peut-être le sage parmi les fous. C'était une mise en question totale de la société et de l'humanité que cette nouvelle proposait. Ce n'était pas cet écrivain, ce peintre, qui était fou, c'était peut-être toute la société qui l'était. C'est un écrit d'adolescence qui dit que tout le monde autour de soi n'est pas le monde réel. Le monde réel était peut-être ailleurs.

V. \& I. - Un lecteur qui voudrait aller plus loin dans la connaissance de ton enfance et de ton adolescence pourrait se fier absolument à tout ce qui est raconté dans Adieu Babylone?

N. Kattan - Je crois. Adieu Babylone, je l'ai appelé roman parce que c'est romancé. J'ai biffé certaines choses, je les ai changées, et parce que je raconte des événements historiques, je ne voulais pas tomber dans la difficulté du documentaire. Parce qu'il y a une difficulté à écrire un livre documentaire où l'histoire doit être très étudiée. Si j'avais voulu écrire des mémoires, j'aurais dû aller aux journaux de l'époque pour voir ce qui s'était vraiment passé, pour que ce soit exact. Or, je ne voulais qu'écrire un roman basé sur une mémoire, telle qu'elle était revécue au Canada (parce que je l'ai écrit au Canada) par quelqu'un qui a transporté avec lui sa patrie. Dans un texte que j'ai publié il y a très longtemps, mon premier texte sur l'Irak, ça s'appelait d'un Monde à l'autre (dans les Écrits du Canada français) je mets en exergue ce mot de Chateaubriand qui dit: Chacun de nous transporte en lui sa patrie. C'est ça que j'ai voulu. Ce que j'avais transporté en moi, je voulais le transmettre. Mais je ne voulais pas le transmettre comme document, je voulais le transmettre comme ce qui était vivant encore en moi. C'est-à-dire que c'était une mémoire vivante et ce qui n'était pas mort était là. Ce ne pouvait être qu'un roman. Donc il y a beaucoup de choses qui ne sont pas documentées mais qui sont pour moi réelles et vraies. Et je dois dire que tous les Irakiens de Bagdad, Juifs et non-Juifs, qui ont lu le livre, et j'en ai eu énormément de témoignages, se sont reconnus dans ce livre. C'est un des rares livres écrits sur l'Irak qui ait porté sur la communauté juive. Et ceux qui l'on lu ont retrouvé cette communauté. Et on m'en a beaucoup parlé, sur ce plan-là. 
V. \& I. - Il y a beaucoup de pudeur dans ce récit et même le narrateur ne se nomme jamais. C'est voulu?

N. Kattan - Oui. Il y a une chose qui m'a beaucoup frappé, un jour quand j'étais à Paris. C'était la première année de mon arrivée à Paris. Un soir, les étudiants de lettres - j'étais à la Sorbonne - étaient invités à une soirée plus ou moins privée, on allait être une trentaine, avec Albert Camus. Albert Camus qui était venu aussi du milieu oriental, mais enfin qui n'est pas oriental comme moi... c'était en 47 je crois cette rencontre avec Camus, et on lui parlait à l'époque de Kafka, de Melville, de Henry Miller, de tout ce qui était intéressant à l'époque, et de la guerre d'Algérie... Et il a dit une chose qui m'a beaucoup frappé et qui s'est confirmée après, en moi, il a dit: En Orient, l'érotisme est vécu, on n'en parle pas parce qu'il y a une pudeur. Et ça s'est confirmé après, pour moi, dans toute mon exploration du discours arabe, du discours oriental. Le mien et celui des autres. Je ne peux plus dire à cet égard que je suis tout à fait Arabe. Il y a deux aspects de ce discours arabe qui expliquent un peu peut-être mes écrits. D'abord on parle beaucoup mais l'essentiel, ce qui est le plus fragile, quand il est encore fragile en nous, on ne le dévoile pas parce qu'on a honte de cette fragilité. Non pas honte d'être faible, mais honte d'être fragile et se dévoiler c'est déjà presqu'abîmer ce qui est ressenti. Il y a donc là une difficulté d'expression. Il y a beaucoup de célébration et d'éloges dans l'expression arabe mais peu d'expression intimiste, car elle brise la fragilité. Dans le discours arabe, il y a beaucoup de mots, les gens parlent beaucoup mais l'essentiel est très peu dit. Mais il est exprimé quand même. L'amitié, l'amour sont exprimés par des gestes, par une présence et c'est là toute mon idée du théâtral et du non-théâtral. C'est le premier élément. Le deuxième élément dans le discours qui vient de mon enfance et qui est de ma culture, c'est de dire aux autres ce qui leur fait plaisir, même si c'est pas tout à fait vrai. Contre cela, moi, j'ai beaucoup regimbé, j'étais contre. Donc dans mes écrits, peut-être pas dans Adieu Babylone mais plus tard, dans presque tout ce que j'ai écrit, j'ai choisi de ne pas écrire en style fleuri pour ne pas plaire par l'exotisme ou pour faire plaisir aux autres, pour leur donner ce qu'ils veulent entendre. D'où ce besoin d'écrire quelque chose de très très sec dans un certain sens. L'autre aspect de ça, c'est que c'était une manière de ne pas mentir. C'était tromper plutôt que mentir, que de dire aux autres ce qu'ils voulaient entendre, et pour moi c'était à la longue insoutenable. Pas parce que c'était simplement le mensonge ou la tromperie, mais parce que, à un certain moment, on en arrive au point où il faut dire les choses telles qu'elles sont. Sans affabulation. C'est pour ça que je me suis éloigné de certains discours arabes, j’ai accepté la pudeur mais je me suis éloigné du discours fleuri et du discours qui fait plaisir. Je me suis rendu compte de cela, lorsque j’ai écrit la Fiancée promise : je n'ai rien dit, mettons, pour faire plaisir aux Québécois, aux Canadiens français... je ne leur dis pas que je les aime, je n'ai pas besoin de le dire, j'en fait partie de cette communauté, je vis là... après trente et un ans, je n'ai pas besoin de le dire, ça doit se savoir. Certains des lecteurs - et ça je l'ai su après par la réaction - ont senti que peut-être je ne disais pas assez mon attachement à mon nouveau milieu. Moi je pensais que ça sortait de chaque page, je n'ai pas éprouvé le besoin de le dire explicitement. 
V. \& I. - A propos, quand tu dis Adieu Babylone, tu ne dis pas Au revoir et quand tu dis Babylone, tu ne dis pas Bagdad. Il me semble que ça mériterait quelques commentaires. Pourquoi Adieu et pourquoi Babylone?

N. Kattan - Commençons par Babylone. Babylone c'est une appartenance à la communauté juive. D'ailleurs, je mets en exergue une citation de la Bible où je dis que si nous, en tant que communauté, sommes arrivés en Irak, ça été en tant que prisonniers à Babylone. Je me rattache donc à cette communauté qui survécut au même endroit pendant vingt-cinq siècles. Nous sommes des Juifs babyloniens. Des Juifs qui, une fois arrivés en Irak, ont eu après quelque temps, quelques générations, le choix de retourner en terre d'Israël. Mais entre-temps, ils ont construit toute une culture, ils ont écrit les commentaires de la Bible qui constituent le Talmud, c'est à Babylone que le Talmud a été écrit, ils ont fait une culture juive en Irak qui est une culture très importante, pour le judaïsme entier. Ils ont, si l'on veut même, écrit les livres des prières. Alors donc Babylone, pour moi, c'est la patrie antique. Bagdad est une ville plus récente qui n'est d'ailleurs pas loin de Babylone, à cinquante kilomètres. Adieu Babylone raconte donc la fin d'une communauté juive à Babylone, c'est-à-dire la fin d'une grande histoire. Ce n'était pas Adieu Bagdad parce que Bagdad continue, l'Irak continue. Mais Babylone, comme histoire d'une communauté juive antique, peut-être la plus ancienne qui ait survécu, c'est peut-être la communauté juive la plus ancienne qui a eu une continuité sans interruption pendant vingt-cinq siècles, mais dont l'histoire est maintenant terminée: ils sont tous partis ailleurs, l'histoire est terminée.

Je dis Adieu aussi parce que cette vie-là on ne la retrouvera pas. Et moi j'ai dit Adieu au Canada: là, je crois que c'est très important que je raconte une histoire qui m'est arrivée mais qui n'est pas une anecdote. Il y a deux ans, il y a un Musulman, en Israël, qui a lu Adieu Babylone et a décidé d'en traduire un chapitre en arabe. Il l'a fait et me l'a envoyé après. Et j'ai lu Adieu Babylone qui se passe dans un pays arabe traduit en arabe. Ç'a été une expérience très dure et très étrange. Dure tout de même parce que je ne m'y suis pas reconnu, écrit dans ma langue maternelle. Je lisais ce chapitre que j'ai écrit moi-même et je ne me reconnaissais pas. Je me suis donc dit: Mon Adieu n'est pas simplement la fin d'une histoire mais aussi le début d'une autre vie. Je l'ai écrit en français et je l'ai écrit à Montréal, ce livre. Je l'ai publié à Montréal avant de le publier en France et avant qu'il ne soit traduit ailleurs. Pour moi, mon lecteur est, enfin, je dis: canadien mais je pense surtout à Montréal, ma ville, je ne l'ai jamais quittée depuis mon arrivée même.si les circonstances m'y ont invité, donc j’ai écrit pour un lecteur montréalais et un lecteur francophone, dans un sens plus large. Quand je me suis lu en arabe je ne me suis pas reconnu parce que le livre est écrit pour ma nouvelle vie. Je dis adieu à l'autre vie parce qu'il y en a eu une autre, entretemps, et cette autre est là: c'est une métamorphose. Je ne nie pas l'autre. J'ajoute à ma nouvelle vie toute une dimension qui est Babylone-Bagdad mais qui fait partie de moi, mais en tant que Canadien, comme Montréalais, Québécois, Canadien. Je suis là et c'est ça ma vie. 
V. \& I. - On peut comprendre que cet $\boldsymbol{A d i e u}$ est un adieu à la captivité puisque qu'en rappelant l'origine tu rappelles la captivité. Et quand tu portes en exergue l'épigraphe qui est là à l'entrée du texte, avec: Nabuchodonosor amena captif à Babylone ceux qui échappèrent à l'épée et furent assujettis à lui et à ses fils, alors ça signale bien ce que tu quittes. Quoi que tu veuilles en dire, tu quittes aussi un milieu de captivité pas seulement celui d'il y a vingtcinq siècles.

N. Kattan - Que j'ai ressenti pour beaucoup d'autres raisons que des raisons religieuses. J'ai senti que c'était un milieu de captivité parce que c'était un milieu où la totalité de mon être ne pouvait pas s'exprimer.

V. \& I. - Ensuite, ce qui est important pour moi, c'est que c'est tiré des Chroniques dans la Bible, non seulement donc la référence biblique mais aussi la référence à un type de récit biblique qui est celui des Chroniques. Or tu vas tenir une chronique mais tu vas la tenir de façon personnelle, intime quand même, avec toute la pudeur qu'on y reconnait. C'est donc dans le sillage de l'écriture biblique mais c'est un discours personnel, auto-référentiel, que tu vas tenir, ce qui est plutôt rare dans le modèle biblique?

N. Kattan - Oui, mais de toute manière quoique dans mon enfance le modèle biblique était très très important. Je raconte d'ailleurs dans Adieu Babylone les histoires que me racontait ma mère. L' histoire biblique est une histoire familiale. Mon grand-père s'appelait Joseph et il a eu trois fils dont deux qu'il a appelés Menashi et Ephraïm de sa deuxième femme. De sa première femme il a eu beaucoup d'autres enfants mais qui étaient des demioncles pour moi. Alors mes deux oncles avaient, comme mon grand-père, des noms bibliques. Et il y a eu aussi autre chose. C'est que mon oncle Ménashi avait ses frères aînés. Quand mon grand-père est mort, ils ont pris tout l'argent à Ménashi, ils l'ont dépouillé, il ne lui restait plus rien. Alors il est parti à 16 ans, un peu plus jeune encore que moi, à dos d'âne en Iran...

Et quand, des années plus tard, ils ont eu besoin de lui, parce qu'ils n'avaient plus d'argent, étaient malades ou veufs, il les a aidés et leur a donné de l'argent. Il ne leur a même pas dit qu'il leur en voulait. Il n'était même pas question de pardon. C'était pour moi l'histoire de Joseph et de ses frères qui était revécue. Et mon oncle qui était pour moi parfois même plus qu'un second père, qui était très important dans ma vie, que j'ai retrouvé. en Amérique puisqu'il était aux États-Unis, cet oncle-là était le grand amour familial de ma vie. C'était mon modèle dans un certain sens mais aussi mon grand amour. Quand j'étais avec lui je l'aimais et il m'aimait. Il avait des enfants lúi aussi. C'était un amour total entre nous. C'était l'histoire biblique. Pour moi l'histoire biblique est aussi l'histoire familiale. Il y a cette intimité... ma mère me racontait cette histoire biblique comme notre histoire familiale et pour moi la Bible est intime. C'est pas une lecture religieuse. C'est pour ça que quand je lis maintenant, je lis encore la Bible, quand on parle des tribus, tout ça, pour moi c'est de l'intimité parce que j'ai vécu tout ça. Je sais ce que c'est. Je sais ce que c'est les autres tribus à côté. Je ne comprends pas cela comme anthropologie, je le comprends comme chroni- 
que familiale. Oui, dans l'histoire biblique évidemment, je suis très humble par rapport à ça, très humble et en même temps très intime, c'est la grande histoire du peuple juif mais aussi pour chaque Juif c'est son histoire qu'il doit relire là-dedans, je crois.

\section{Paris}

V. \& I. - Le titre anglais des Fruits arrachés se dit Paris Interlude, l'interlude parisien. Est-ce que pour toi ton séjour parisien, entre donc Bagdad et Montréal, a le sens d'un interlude?

N. Kattan - C'est un interlude dans l'existence mais pas vraiment dans la vie. Pour moi, ce n'est pas un interlude et, souvent, j'ai nettement l'impression que je n'ai jamais quitté Paris.

\section{V. \& I. - Pourquoi?}

N. Kattan - D'abord c'était une ville rêvée avant d'y être allé. C'était la ville rêvée dans tous les sens du mot. Et je me souviens quand je suis arrivé à Paris, j'étais boursier du gouvernement français, j'étudiais la littérature, j'avais des rencontres avec beaucoup d'écrivains et je continuais d'écrire en arabe. J'ai fait, par exemple, une causerie à la radio arabe de Paris où je décrivais ma première réaction, après quelques mois de séjour. Je disais, je me souviens encore de ça parce que j'en suis encore convaincu, que le seul endroit qui est supérieur au rêve qu'on en fait, c'est Paris. Il faut dire qu'à l'époque, c'était juste après la guerre, il y avait des difficultés matérielles mais il y avait un bouillonnement, en France, incroyable. C'était la fin de l'occupation, c'était la redécouverte de la liberté, c'était les mouvements de résistances, c'était des mouvements de toutes sortes. Déjà, avant d'y arriver j'avais des rapports avec quelques écrivains surtout, j'avais écrit sur le surréalisme. J'ai donc été accueilli par André Breton comme faisant partie $\mathrm{du}$ groupe surréaliste, je fus donc accueilli assez rapidement. André Gide avec qui j'avais une correspondance, m'a tout de suite reçu, il voulait que j'aille voir Gaston Gallimard et Jean Schlumberger. Je voyais bien que je n'avais rien fait encore, et que je pouvais vivre sur une mystification: prétendre avoir une œuvre en arabe, ce que je n'avais pas en fait. J'avais écrit des choses en arabe mais je n'avais que 19 ans et je n'avais pas une cuvre. Vivre sur cette mystification et dire toujours que j’écris en arabe et, être encore le chef du groupe surréaliste irakien etc... Alors, je ne suis pas allé voir Gaston Gallimard ni Jean Schlumberger et puis j'ai quitté le groupe surréaliste et j’ai été curieux comme journaliste, comme étudiant, puisque j'étais étudiant, vraiment, à la Sorbonne, de voir des écrivains. J'ai vu un tas d'écrivains comme Mauriac, Claudel... J'ai assisté à des tas de débats et puis j'ai participé à des débats avec Jules Romains, Gabriel Marcel, Georges Duhamel, enfin tout un groupe très disparate d'écrivains. J'allais énormément au théâtre, j'y allais presque tous les soirs, j'avais une carte de journaliste alors j'allais gratuitement au théâtre, je pouvais même inviter des jeunes filles puisque j'avais des billets pour deux personnes. Alors j'allais beaucoup au théâtre, j'allais au concert, je sortais tous les soirs, j'écrivais, je lisais, j'étudiais, mais j'écrivais des articles pour les journaux de Bagdad. J'ai mené une vie très intense, et à proprement parler, d'apprentissage. J'ai découvert aussi d'autres parties de l'Europe. J'ai été en Hollande, j'en ai 
appris la langue, je suis allé en Italie, j'en ai appris la langue. Je suis allé en Allemagne, en Suède, au Danemark, en Suisse, en Belgique. J'ai vu aussi d'autres parties de l'Europe. Mais j'ai découvert deux choses qui sont très importantes pour moi, qui m'ont beaucoup marqué depuis ce moment-là.

D'abord j'ai découvert que ma culture arabe n'était ni anodine, ni futile, c'était une culture très importante et très présente puisque c'est sur ça que portaient mes débuts d'écriture en français. On me demandait dans les journaux français - j'ai commencé à éerire dans plusieurs journaux comme l'Opéra, la Gazette des lettres, Combat, des revues comme l'Âge nouveau à partir de 48-49. C'était sur la culture arabe, la poésie irakienne, la poésie égyptienne, le roman libanais, je commençais à écrire sur ces sujets-là dans les journaux français et parfois aussi européens, en Suisse, en Belgique et en Hollande. J'ai découvert que j'appartenais à cette culture et qu'il y avait quelque chose à en dire que les Européens ne savaient pas, ne connaissaient pas. J'étais quelqu'un qui portait une culture et qui pouvait la transmettre.

Et la deuxième chose que j’ai découverte, c'est que la culture européenne que je croyais omnipuissante et omniprésente était en fait très relative, c'està-dire je croyais moi dans mon pays à quatre-vingt dix pour cent d'illettrés, qu'il suffisait d'aller à l'école pour être affranchi et être cultivé. Or, je voyais des gens qui sortaient des facultés et qui avaient des doctorats et qui n'étaient pas affranchis, d'après ce que je voyais, dans leur esprit. Alors ça a créé une relativité dans mon esprit entre savoir et connaissance, ou je faisais, bien plus tard, la distinction entre savoir et connaissance et je pouvais me dire à ce moment-là que l'on pouvait être un bédouin illettré et avoir des connaissances et être un docteur ès n'importe quoi et ne pas être affranchi d'esprit ni être éclairé. C'est cette double relativité de la pesanteur et du poids d'une culture archaïque (mais présente) et d'une culture très puissante (mais qui pour moi n'était pas la seule) qui ont fait que je commençais à me poser des questions sur mon propre itinéraire. Et la première question que je me posais c'était : comment conserver en moi ce qui était d'oriental sans rien rejeter de l'Occident, parce que j'étais attiré par l'Occident, pas seulement attiré, je l'absorbais, je le buvais, j'en vivais, j'en rêvais et j'étais entièrement pris làdedans, je trouvais que c'était énorme, je n'arrêtais pas de trouver des aliments et de la nourriture.

V. \& I. - Revenons aux Fruits arrachés. Sur la page couverture de l'édition française on a mis l'image d'une femme. Est-ce que tu dirais que c'est d'abord là le sens de ton interlude parisien.

N. Kattan - Oui, je crois qu'il y a beaucoup de femmes et ça peut-être, à mon avis, les critiques ont peut-être parfois mal vu ou mal lu ce que ça voulait dire. D'ailleurs, c'était toujours mêlé, quand je parle des femmes, à la découverte d'une culture. Je parle d'une Polonaise, c'était tout un côté slave que je découvrais. Je parle d'une Hollandaise, c'est toute une culture germanique, hollandaise. La Française dont je parle... où j'allais dans des châteaux, de grandes maisons en province, c'était toujours toute une société que je découvrais. C'était pour quelqu'un qui est l'étranger mais qui ne voulait pas être étranger. C'était quelqu'un qui vient de l'extérieur. Il arrive dans une société et il n'y a qu'un moyen de pénétrer cette société, par son 
désir, son désir de pénétrer cette société. Or, le chemin le plus court, c'est un circuit d'ordre affectif. On ne peut pas aimer une ville sans aimer ses habitants. Alors, les habitants, pour un jeune homme, ça passe d'abord par le circuit le plus rapide et le plus intense, le plus riche, il faut le dire, c'est celui de la femme. Et à partir de la femme, on a des amis. J'ai conservé jusqu'à maintenant, je vois encore quand je rentre à Paris, des amis que j'ai eus il y a trente-huit ans. Je les vois encore, c'est toujours les mêmes amis.

Les femmes sont sorties parfois de ma vie, j'en ai gardées un certain nombre comme amies, mariées, avec des enfants etc., mais elles sont restées comme amies. Mais pour la personne qui arrive dans un pays, c'est normal que ce soit le plus court chemin. Il y a ce besoin de ne pas être exilé et de ne pas être exotique. Quelle est la solution? La solution c'est d'entrer dans la société qui nous fascine, de ne pas la regarder derrière une vitre ou comme dans une vitrine mais de rentrer dans la boutique, de rentrer dans la maison, d'être là, d'être l'un des acteurs. Le seul moyen de le faire c'est d'être avec une femme qu'on aime et ça se fait comme ça.

V. \& I. - Il y a une marque discursive qui est frappante quand on passe d'Adieu Babylone aux Fruits arrachés, c'est l'importance tout à coup que prend le dialogue. Qu'est-ce que pour toi signifie cette marque discursive? Est-ce que tu rattaches ça à ta volonté d'échange? Il y a une sorte de volonté échangiste extraordinaire qui est marquée dans toute ton œuvre. Alors que c'était mois utile, ou en tout cas moins pratiqué, dans Adieu Babylone, parce que le milieu lui-même nécessitait, je pense, un peu plus de descriptif, avec Paris et avec les Fruits arrachés, qui en constitue la chronique, là on sent vraiment, et peut-être que c'est attribuable justement au rapport à la femme, on sent précisément l'importance du dialogue qui s'installe et qu'on ne va pas quitter pour le reste de l'œuvre. D'ailleurs certaines de tes nouvelles se donnent uniquement en dialogues, avec à peine un descriptif qui court par-ci par-là.

N. Kattan - Je crois que je ne m'en suis pas rendu compte en écrivant les Fruits arrachés. On m'a souvent demandé pourquoi, comment, je choisis moi d'écrire un roman plutôt qu'une nouvelle ou une pièce de théâtre, ou un essai. Je me suis rendu compte que quand je veux décrire, j'écris des essais. C'est une description intellectuelle, conceptuelle mais c'est à la première personne. Ce n'est pas un discours didactique, c'est un discours autobiographique, méditatif, mais d'observation. Pour moi, c'est une forme de description. Quand il s'est agi d'Adieu Babylone, je ne voulais pas décrire une société ni faire, ni raconter l'historique d'une communauté ou d'une société mais vraiment narrer. C'était un conte qui se prolongeait. Je racontais. C'était un récit si on veut mais pour moi c'était un roman. Quand je suis arrivé aux Fruits arrachés et après à la Fiancée promise, je trouvais que décrire le Paris des années 50, fin des années 40 et les années 50, m'était une entreprise futile, déjà faite mille fois et qui n'avait aucun intérêt pour moi. Ça m'ennuyait déjà. J'ai tellement lu d'études, d'articles sur la fin de la guerre, et tous les écrivains français, américains, allemands, il y a des dizaines de livres là-dessus. Et pour moi, le Paris de l'époque n'existait, dans ma mémoire encore là parce que j'étais déjà au Canada et c'était une question de mémoire et pas de souvenir, n'existait pas dans ma mémoire comme un 
environnement, un état, mais c'était des personnes et ces personnes me faisaient vivre les lieux. C'était une vie de désir de rapport avec les autres. Alors ce rapport avec les autres, qu'ils soient hommes ou femmes ne se faisaient que dans la mesure où moi je pouvais parler mais que je pouvais aussi recevoir une réponse. J'attendais de l'Occident une réponse et cette réponse-là me mettait en question et j'acceptais cela. Il n'y avait personne dans Adieu Babylone qui pouvait me répondre parce que je décrivais quelque chose qui s'était passé. C'était déjà une histoire en soi, c'était la mémoire descriptive. Mais quand je suis venu aux Fruits arrachés, il y avait la réponse de l'Occident et c'était la réponse que moi j'ai reçue comme Oriental et c'est très circonstancié et c'est très spécial mais je crois qu'il y avait là une mise en question, même de moi, et de l'Occident. Mais il y avait aussi ce que certains lecteurs ont remarqué mais qui a malheureusement passé inaperçu pour les critiques, il y avait une ironie, il y avait déjà une forme d'ironie dans ce que j'ai écrit dans Adieu Babylone... C'était de l'ironie tournée vers soi, je m'amusais moi-même, c'est une ironie un peu juive, un peu orientale. Quelqu'un qui se moque de lui-même.

Il y a dans les Fruits arrachés beaucoup de cette forme d'ironie. Le grand amoureux qui est toujours bafoué, ça ne marche pas, pas parce que lui-même est malhabile ou que les femmes le sont, mais parce qu'il y a dans les rapports humains une absurdité inattendue à laquelle personne n'est préparé au départ. On ne prépare pas les rencontres. Ces rencontres-là se nouent et se dénouent. Si on ne veut pas trop souffrir de voir la fragilité de ces rapports, la seule chose qui nous reste pour leur donner pesanteur et intensité, c'est une distance d'ironie. C'est-à-dire être tout à fait là-dedans mais être aussi à distance pour ne pas pleurer, pour ne pas dire: Bon, voilà. Je regardais avant cette entrevue toutes les lettres, tout ce qui correspondait à cette époque de ma vie et je me disais que toute vie est faite de certaines options, de certains choix mais il n'y a qu'un choix à un certain moment. Ma vie par exemple, à l'époque des Fruits arrachés était une vie toute ouverte, une existence ouverte à des tas d'avenues. Et quand je vois toutes les histoires terminées, je me dis qu'il y a eu des morts et que pour accepter ces morts, il ne faut pas le faire en blessé. Il faut les accepter un peu à distance parce que la mémoire n'est belle et n'est riche que dans la mesure où on ne la réduit pas à des blessures. Toutes les femmes qui sont parties de notre vie, tous les amis morts... J'ai des lettres d'hommes déjà morts, je me suis dit que ma vie est riche de toutes ces présences mais qu'il ne faut pas que je les réduise à des blessures, que les amours terminées sont venues s'ajouter à d'autres amours qui les ont couronnées. Dans les Fruits arrachés il y a cette ironie que j'ai voulue, peut-être que je n'ai pas réussi mais ça l'écrivain veut mais son talent ou ses possibilités sont ses limites aussi...

V. \& I. - Alors qu'Adieu Babylone a été vraiment très bien reçu, presqu'acclamé pour tout dire, les Fruits arrachés n'ont pas reçu une si bonne réception. Je me souviens d'un critique qui a dit qu'il trouvait ces fruits-là un peu secs.

N. Kattan - Tout ce que j'ai publié, je l'assume aujourd'hui entièrement. Je ne crois pas que j'aie publié quoi que ce soit que je n'aie pas voulu publier. Donc les Fruits arrachés c'est pour moi un livre qui était achevé. C'est ça 
aussi la grande difficulté que j'ai comme écrivain et ça, je crois que ça ouvre, si tu veux, le dossier de la réception qui m'est faite aussi bien au Québec qu'au Canada anglais, aux États-Unis qu'en Europe. En regardant tous les articles, les papiers qu'on a faits sur moi, j'ai vu par exemple, c'est une parenthèse que j'ouvre, qu'il y avait quatre lectures différentes qu'on a faites d'Adieu Babylone, en France, aux États-Unis, au Canada anglais et au Québec et, après, en Israël. Je ne me prête pas à la fixation et d'ailleurs je termine le Réel et le théâtral en disant: je refuse tout ce qui me fige et me fixe. C'est un appel, pour moi, très important. D'ailleurs à partir de Bagdad je n'ai pas voulu être que Juif. Je voulais être aussi culturellement Musulman. En Europe, j'ai voulu aussi être culturellement Français et connaître le christianisme et j'ai fait beaucoup d'efforts pour le faire mais c'était là, pas besoin d'efforts, c'était là prêt à être absorbé. Ce qui fait que, comme je ne me présente pas d'une manière très visible, d'un bloc — je suis Juif de Bagdad mais je suis devenu beaucoup d'autres choses - les gens qui lisent disent qu'il n'y a pas le Juif exotique de Bagdad qui voit l'Europe. Qu'est-ce qu'il est alors? Il est aussi Européen. On ne peut pas me mettre dans un moule et c'est ça qui a fait que pour moi si mon œuvre est réussie à la fin, je crois que j'ai encore des livres à publier qui sont écrits déjà et d'autres, s'il y a un ensemble qui se constitue, c'est dans toute cette mosaïque de formes: l'essai, la nouvelle, le théâtre aussi bien que le roman; et dans toutes les cultures que j'ai essayé d'absorber, c'est dans cette double mosaïque que se crée l'ensemble. C'est merveilleux quand ça marche parce qu'on dit Voilà un écrivain qui a un côté universel, qui a un côté çi, qui a un côté ça... Mais la difficulté est grande quand on écrit un livre et qu'on le publie quand on n'a pas un public précis déjà. J'ai écrit Adieu Babylone pour des Québécois de Montréal, mais c'est sur Bagdad. Alors les Bagdadiens le découvrent surtout en traduction anglaise, dix ans après. Je n'ai pas de public à Bagdad, je n'ai plus de public là. J'écris les Fruits arrachés, et les Européens ne s'intéressent pas à ça parce que c'est très spécial et c'est très marginal pour leur vie. Un éditeur français m'a dit: Il y a tellement de livres sur Paris et il était très hésitant, il ne l'a pas pris finalement. Je n'ai pas fait d'efforts non plus, je ne l'ai envoyé qu'à un seul éditeur et puis quand ça n'a pas marché j'ai dit: un jour ou l'autre ça va être publié en France. Avec toutes ces diverses facettes, j'ai de la difficulté à être reçu.

J'accepte ces facettes aussi mais je suis d'abord un écrivain francophone du Québec, ça pour moi c'est très important et j'insiste pour publier d'abord ici. J'ai eu des difficultés d'édition mais c'est pour moi une prise de position très importante parce que je n'ai que ce public-là. Il faut avoir un public et je n'ai que ce public-là. C'est mon public, qu'il l'accepte ou qu'il ne l'accepte pas, je n'en ai pas d'autres! Ou les autres viennent après. Quand des Juifs francophones, des Juifs anglophones viennent vers moi et me disent: Vous êtes un écrivain juif?, je vais dire Oui en partie parce que si on voit bien mon œuvre, elle n'est pas que juive. Dans les Fruits arrachés elle n'est pas que ça. Dans la Fiancée promise il n'y a pas que ça. C'est une partie de moi, bien sûr, et je ne le nie pas mais dans mes essais, dans mes critiques, il y a tout ça mais il n'y a pas que ça. Donc, je ne suis pas ce qu'on peut dire, classé: l'écrivain juif, non. Je suis ça mais je ne suis pas que ça. 
Alors, ça fait beaucoup de choses que j'accepte parce que je ne veux nier aucune facette, aucune dimension de mon être mais ça me crée des problèmes de réception. Surtout, ça m’a créé au départ un problème de réception au Québec parce que mon premier livre est publié en 1970 à l'époque où l'indépendantisme, le séparatisme étaient très importants. Je n'étais pas contre mais je n'en faisais pas partie, j'étais à Ottawa, je n'ai pas adhéré à cela, je travaillais au Conseil des arts, bon. J'aurais pu être séparatiste tout en travaillant au Conseil des arts, j'aurais pu faire ce choix, mais j'avais une autre idée, je l'ai écrit dans mes livres, de la territorialité. Je suis pour la culture française absolument, pour sa défense et son illustration au Québec et au Canada mais pas pour une territorialité politique, mais ça c'est un autre problème mais pour moi c'était très important à l'époque et j'étais honnête avec moi-même, avec tous ceux qui m'entouraient. Mais ça m'a créé des problèmes parce qu'on attendait beaucoup de moi qui étais l'un des premiers francophones non catholiques à s'exprimer, et je dois dire que quand je suis arrivé au Canada en 54 et que j'ai fondé le Bulletin du Cercle juif qui était la première publication non catholique de langue française au Canada et ç'a été accueilli à l'époque comme un phénomène incroyable, avec les éditoriaux d'André Laurendeau, de tout le monde, comme un phénomène nouveau dans la vie culturelle... on était sous Duplessis à cette époque-là et l'Église catholique gouvernait tout et moi je sortais un Bulletin qui était juif et qui parlait du judaïsme et qui n'était pas catholique, et en français, sans demander la permission de personne. J'ai été pourtant reçu par tout ce qui était cultivé et par aussi l'Église et très bien, parce que je n'étais pas contre l'Église non plus, j'étais différent mais je n'étais pas contre et j'ai gardé d'ailleurs des amitiés dans le clergé que je garde encore parce que j'admire tout ce qui est religieux et j'ai beaucoup d'amitiés avec des membres du clergé quand ils sont vraiment religieux. Et soudain le réveil se concrétise. Moi qui étais l'un des premiers à avoir adhéré, à avoir montré un intérêt pour ça, j'ai fait de multiples conférences, j'ai parcouru le Québec, il n'y a pas un club Richelieu où je ne sois pas allé, une C.S.N., une Chambre de commerce des jeunes, je ne sais pas où je ne suis pas allé... j'ai montré mon adhésion à la collectivité et quand vient le réveil... tous mes amis d'ailleurs qui étaient au gouvernement du Québec et d'autres intellectuels, qui prennent cette option-là, et moi qui n'en suis pas... Et le Réel et le théâtral, qui est une réflexion qui n'a rien à voir avec ça, ne mentionne même pas ça. Et je me souviens qu'à l'époque il y avait quelqu'un (c'était Ivanhoé Beaulieu je crois) qui écrivait dans le Soleil, qui disait que même si on n'y parlait pas du Québec, c'était un livre québécois. C'était gentil, c'était vrai, mais à l'époque il fallait vraiment ne pas être absorbé par le milieu ambiant pour le dire. Parce que je l'étais Québécois et c'était une adhésion très ferme mais je l'étais à mes conditions. C'est-à-dire que j'apportais au Québec ce que j'étais, je ne faisais pas que célébrer ce qu'était le Québec comme je n'avais pas voulu célébrer la 'France. C'était modeste et humble ce que j'avais, mais je voulais l'apporter, je ne voulais pas seulement recevoir, je voulais dire: Voilà, je viens de l'Orient je vous donne ça, ce que je suis. Je dois dire que c'était assez bien reçu. On ne m'a pas nié, ou renié mais ce n'était pas le moment. Le Québec était absorbé par lui-même. 


\section{Montréal}

V. \& I. - Et quand tu viens en Amérique pour y rester, tu arrives à Halifax. Pourrais-tu rappeler comment ça c'est passé? Parce que, si ton œuvre n'a pas toujours eu la réception attendue pour des raisons que tu nous a montrées, comment toi, comme individu as-tu été reçu ici?

N. Kattan - Je raconte ça dans l'Arrivée, un texte que j'ai publié dans les Écrits du Canada français, numéro 19. C'était en plein hiver, au mois de février 54, il faisait très froid bien sûr, et moi je n'avais jamais autant vu de neige, j’avais vu de la neige un peu en Europe mais pas comme ça. À Halifax, en descendant du bateau, c'était un bateau d'immigrants, il y avait des services d'aide aux immigrants, et à la sortie il y avait deux personnes de chaque côté. Quand on descendait du bateau on vous demandait: Est-ce que vous êtes catholique ou protestant? Quand on était catholique on recevait le Devoir et une carte du Canada en français et quand on était protestant, on vous donnait the Montréal Star et une carte du Canada en anglais. Moi j’ai dit: Non. je ne suis ni catholique ni protestant. Alors je suis passé entre les deux rangs, et n'ai eu ni carte, ni journal! C'était ma première expérience. J'ai pris ça avec humour parce que la manchette du Devoir de ce jour-là et que j'allais lire dans le train, disait, hasard incroyable: 500,000 chômeurs au Canada. Je me dis alors que puisqu'on ne m’a pas donné de journal, ça ne me regarde pas! Au départ, il me fallait savoir où était mon chemin. Je décris ça un peu dans la Fiancée promise: je vais chez les Juifs, mais je ne parle pas yiddish, ma langue c'est le français, je parle anglais mais ma langue c'est le français, c'est un peu spécial, on m'accepte comme ça, comme quelqu'un de spécial. Je vais aussi chez les francophones, on me dit: $A$ quelle paroisse vous appartenez? C'était nouveau qu'un Juif parle français et qu'il vienne chez les Canadiens français. C'était toujours à la recherche de travail. Je vais chez les anglophones et on me dit: Mais pourquoi vous n'allez pas chez les vôtres? (les juifs). Il y a quelqu'un qui m'a dit, je me souviens encore d'une interview qu'il m'a faite, il m'a dit: De quelle nationalité vous êtes? Je lui dis irakienne. Alors il me dit: Oui, mais c'est quoi fa Irakien, vous êtes Musulman?, je dis: non, alors il me dit: Vous êtes de nationalité juive?, je dis: ce n'est pas une nationalité, il me répond: Il fallait le dire, pourquoi vous n'allez pas chez-vous? Il fallait, et c'était un choix à l'époque, me dire que j'étais refusé par tout le monde ou me dire c'était ma chance de n'appartenir à personne. Comme cela je pouvais voir ce qu'il y avait à faire entre tous ces groupes. La première chose que j'aie pensée, c'était encore ma vieille préoccupation de l'échange, je suis allé à la communauté juive et je leur ai dit: Comment ça se fait que vous vivez parmi les Canadiens français et que vous ne faites rien en français, il y en a parmi vous qui connaissent le français, avocats, commerçants, etc., médecins, moi je vous propose de faire un bulletin, une publication en langue française, f̧a ne vous coutera pas cher, je leur ai promis que ce serait ronéotypé, qu'on le ferait sans aller à l'imprimerie... Dès le premier numéro, il y a eu des éditoriaux dans la Patrie, dans le Devoir, il y avait un tel intérêt qu'ils ont dit: Mais on ne savait pas que c'était si important, que les Canadiens français allaient nous accueillir tellement bien! À partir du troisième numéro, c'était déjà imprimé. C'était un petit bulletin mais à l'époque c'était important pour les rapports de 
groupe. C'était avant le nouveau nationalisme, on était encore sous Duplessis, on était encore sous l'Église catholique. Et l'Église catholique a très bien vu ça, parce que je n'attaquais personne, c'était une description et j'invitais même des prêtres à venir parler aux Juifs, leur dire ce que c'était que la culture canadienne-française. À partir de ce moment-là j'ai circulé dans le clergé d'une manière incroyable, j'ai été invité à écrire dans Relations sur les Juifs. C'était quelque chose, à l'époque, la revue des jésuites qui invitait un Juif à écrire sur le judaïsme, c'était le père Arès qui me l'avait demandé. De son côté le père Lévesque, devenu un de mes grands amis, m'a invité à aller faire une conférence à ses collègues dominicains à Québec. J'ai connu l'Abbé O'Neil, tous les gens qui circulaient à l'époque. La première interview qu'on m'a demandée, c'était avec René Lévesque; après: avec Marcel Barthe, Judith Jasmin, puis André Laurendeau, Jean-Marc Léger qui m'a interviewé pour la Presse et m'est devenu un ami. J'ai rencontré, à cause de cette nouveauté que je représentais, beaucoup de gens qui sont ainsi devenus mes amis comme aussi Jean-Louis Gagnon. Pour eux, c'était le temps de l'ouverture et moi je représentais une forme d'ouverture. Comme j'étais entièrement absorbé par ça, je me souviens des conversations que j’avais avec Laurendeau, on se voyait tous les mois, on allait déjeuner ensemble pour simplement discuter, c'était devenu la grande amitié, très profonde, dans la différence la plus incroyable mais avec une affection très profonde. Je lui disais: j'ai lu telle chose dans l'Action nationale ou j'ai lu ça dans telle revue, je lisais tout ce qui paraissait au Québec, et il disait: Quelle patience vous avez à lire tout ça, vous m'apprenez des choses sur le Québec, sur le Canada français! Ce n'était pas de la patience, lui savait tout ça, l'Action nationale il en avait été le rédacteur-en-chef à un certain moment, il était là-dedans, il n'avait pas besoin de tout lire. Je lisais tout ce qui paraissait. Il était très intéressé, c'était devenu une grande amitié. Je n'avais pas besoin de dire quand j'écrivais que je les aimais ou que je ne les aimais pas, je faisais partie du groupe. Ils m'ont accepté comme faisant partie d'un groupe et c'était déjà mon pays. Quand j'ai écrit la Fiancée promise je n'avais pas besoin de dire: Ah je suis' venu, le Québec a été merveilleux, il m'a absorbé, il m'a fait ci... Non je n'avais qu'à dire que j'ai rencontré telle ou telle personne, elle m'a dit telle et telle chose et puis je n'ai pas dit que les bonnes choses, j'ai dit aussi les choses qui m'ont beaucoup heurté et puis les choses qui étaient fermées. C'était fermé pour lès Québécois aussi, ce n'était pas fermé que pour moi. Ce qui m'était fermé, l'était aussi pour les Québécois.

V. \& I. - Quand on lit la Fiancée promise, on peut reconnaitre assez facilement les André Laurendeau, René Lévesque, Jean-Louis Gagnon ou Judith Jasmin. Est-ce qu'il en va de même pour celle qui allait devenir ta femme?

N. Kattan - Avec les femmes c'était différent. C'était encore la porte. Comme pour les Fruits arrachés, c'était la manière de pénétrer le pays, de connaître le pays; ce n'était pas seulement un besoin de multiplier les aventures érotiques, c'était la première porte ouverte pour connaître le Canada français et entrer dans une famille. Entrer c'était sortir... ça ne se fait pas comme ça, ce n'est pas programmé, je n'ai pas voulu sortir... Quand 
j’ai rencontré Gaëtane (Laniel), en 1956, je venais de Paris; elle parlait de théâtre, moi je parlais de ça, le sort a fait qu'on avait tellement de choses à discuter qu'on s'est revu, et puis bon! La vie a pris ce cours-là et elle est devenue ma femme parce que c'était la femme qui représentait pour moi, et qui représente encore pour moi un monde, qui est encore très vivant. Ça a présenté des difficultés, pas insurpassables ni trop compliquées finalement. Elle n'est pas directement dans le roman, elle y est mais il y en a d'autres. Chaque femme est un mélange de beaucoup d'autres femmes. Le rapport avec les femmes est beaucoup plus romancé dans la Fiancée promise.

V. \& I. - Pourquoi ce titre?

N. Kattan - Pour revenir à la promesse. C'est-à-dire ... qu'est-ce que c'était pour moi le Canada? C'était une promesse. La terre d'Amérique, la terre de promesse pour ne pas dire la terre promise puisque j'avais utilisé le mot, dans la Mémoire et la promesse, pour une lecture biblique de l'Amérique. Mais cette promesse... le pays c'est une abstraction, le pays c'est une nature. Je ne suis pas un homme qui fait la chasse et la pêche, je ne suis pas un homme de nature. J'aime le paysage, j'aime la nature mais je ne suis pas venu à une nature. Pour moi, donc, cette promesse-là c'est une fiancée, c'est-à-dire c'est une femme qui symbolise tout un pays, mais ce n'est pas une femme, ce n'est pas un pays qu'on a épousé, ça demeure une fiancée, c'est-à-dire dès que la promesse se réalise, il faut qu'il y ait d'autres naissances. Dans la vie privée, oui, ça se fait, j'ai eu un fils (Emmanuel), Dieu m'a donné un fils, j'en ai beaucoup de gratitude mais dès qu'un pays devient une épouse, ce pays est mort déjà, il est institutionnalisé et pour moi le pays, cette terre de promesse demeure une fiancée dans la mesure où il n'est pas institutionnalisé, il n'est pas fait. Je ne le possède pas, il ne me possède pas et je crois que chaque pays est un passage, est élaboration d'une destinée qui n'est pas terminée. Et dans la mesure où elle n'est pas terminée, c'est encore à l'état de fiançailles. C'est après peut-être (après une longue vie, j'espère!), une fois que je serai mort, que l'on verra s'il y a eu un mariage. Je ne veux pas dire; ce serait une prétention pour moi de dire qu'il y a eu un mariage, que c'était déjà consommé. Ce n'est pas consommé, je m'élabore, je me fabrique encore et je ne peux pas me fabriquer tout seul, il faut que je me fabrique avec un pays.

\section{Le projet romanesque}

V. \& I. - J'aimerais revenir maintenant au projet romanesque comme tel. Il y a peu de propositions générales ou peu d'images globales qu'on peut aisément isoler dans ton œuvre, tellement elle est parlée, c'est-à-dire rapportée au niveau des échanges de paroles. Il y a peu de descriptifs, c'est d'une économie extraordinaire pour présenter les personnages, de telle manière qu'on peut même s'y perdre dans les Fruits arrachés, tellement il y a un nombre considérable de personnages, ce qui n'est pas le cas dans la Fiancée promise. Alors, s'il existe une image qui permette d'arriver à cette vue synthétique et de cerner peut-être un peu ce que j'appellerais ton projet romanesque, je la trouverais pour ma part à la dernière page de la Fiancée promise où l'on trouve Meïr en train de parler avec Claudia (c'est la fin du roman, on ne sait pas trop bien d'ailleurs s'ils vont rester ensemble mais peu importe) il lui raconte le rêve qu'il fait. C'est celui d'un funambule qui 
marche dans le vide, sur un fil. Alors je me dis que cette marche sur le fil n'a qu'un objectif: dans le vide global où le narrateur se déplace, il n'y a qu'un objectif, c'est de trouver le plus tôt possible le visage précis de la femme recherchée, déjà aimée. Et alors cette quête de l'autre, sur le fil de la métaphore, apparaît comme une prospection prudente d'un autre qui est forcément féminin, d'où cette thématique de l'amour. Si j'osais, mais peut-être trouveras-tu trop simple cette image (ce cliché!) que j'ajouterais maintenant pour désigner plus généralement ton entreprise stylistique, je ne peux pas ne pas penser aux Mille et une nuits. Tout se passe comme si le narrateur était en voie de réitérer les Mille et une nuits amoureuses. Sans que cela nous ramène pour autant à Schéhérazade. Je ne prétends pas que Meïr ressemble à Schéhérazade. Mais on peut penser que si Meïr est là, que si le narrateur est là sur le fil du texte-récit à venir, il est symboliquement dans la polition d'expression et de narration de Schéhérazade. Et alors se pose peut-être le problème métaphysique de la mort, en tout cas ce que représente ce néant, ce vide auquel il est très difficile d'échapper. Et on n'y échapperait qu'en se tenant correctement sur ce fil du texte et de la mémoire et en arrivant à ces rencontres. Est-ce que cette vue globale de ton projet romanesque te paraît juste?

N. Kattan - Je la trouve plus que juste, je la trouve pénétrante et d'une certaine manière dérangeante mais ce n'est pas grave, je suis responsable de ce que je fais et même si j'essaie de me cacher, je le fais en même temps pour me révéler. J'écris pour me cacher mais aussi surtout pour me révéler.

Je voudrais dire deux mots, d'abord. Quand j'ai fait ce rêve, je n'ai même pas compris moi-même ce que je voulais dire. C'est aussi simple que ça. Cette image était tellement présente en moi, je n'en comprenais pas le véritable impact mais il fallait que je termine ce roman sur cette image-là. C'est presqu'au niveau de l'inconscient poétique si l'on veut. Mais le visage que j'essaie de découvrir, c'est pour contrer d'abord la mort qui est toujours présente puisque mon œuvre se déroule dans le temps, dans une sorte de durée plutôt que dans l'espace. Et c'est pour ça qu'il y a ce vide. Je veux toujours échapper à l'espace pour m'inscrire dans un temps. Mais le temps pose des problèmes plus considérables, et pour le romancier et pour l'homme. D'abord, il y a la mort, bien sûr. Même si on dit qu'on accepte l'idée de la mort, on ne l'accepte pas vraiment, c'est pour ça qu'on écrit. Mais aussi ce qu'on essaie de repousser aussi, ce que j'essaie de repousser dans l'immédiat - la mort c'est une abstraction lointaine, je ne saurais pas dire ce que je serai après ma mort, ça m'est égal - ce que je repousse le plus, et qui m'effraie le plus, c'est l'absence d'abord et, ensuite, c'est l'oubli, d'où cette présence en moi de l'oubli, et le titre de mon prochain livre d'essais: le Repos et l'oubli; l'oubli pour moi c'est l'image, dans la vie actuelle, de la mort. Chaque fois qu'une chose est oubliée, elle est morte. La mémoire est pour moi la durée dans la vie. Le roman, c'est pour ça que mes romans sont autobiographiques, c'est une manière de sauver la mémoire pour échapper à la mort. Tout ça semble très abstrait mais c'est vraiment vécu comme ça au quotidien parce que l'oubli c'est aussi l'absence et j'ai vécu beaucoup dans l'absence. J'ai toujours été éloigné de ma famille, des personnes qui étaient proches de moi. Une fois, dans le questionnaire de Proust qu'on m'avait 
présenté, un écrivain canadien a fait un livre là-dessus, il a posé un certain nombre de questions à des écrivains, je me souviens, ça m'a beaucoup frappé, ça me revient, on m'a demandé quel est le comble du malheur pour vous? J'avais dit: C'est d'être loin de mon fils et de ma femme. Pour moi, c'était les personnes présentes dans ma vie et l'absence pour moi c'est la chose la plus pénible parce que j'ai beaucoup vécu dans l'absence.

Pour les Mille et une nuits, je crois que tu frappes avec une justesse incroyable parce que justement c'est mon prochain roman. Je vais en parler parce que je crois que même s'il n'est pas publié, il est important parce que ça poursuit ce projet romanesque. C'est l'histoire d'un Juif de Bagdad, ça s'appelle la Fortune du passager, celui dont on a dérobé la fortune, l'argent en l'occurrence, mais c'est symbolique la fortune, c'est un terme ambigu, pas ambigu mais à double sens pour moi. Il part à travers le monde pour chercher la personne qui lui a dérobé cet argent. Il va d'un pays à l'autre et dans chaque pays, dans chaque ville où il s'installe pendant quelque temps, il a une vie avec une femme, parfois sans avoir une aventure féminine, simplement une aventure de travail, mais il y a des histoires d'amour, des amours qui se réalisent et d'autres qui ne se réalisent pas. Il va de Tel Aviv à Paris, à Genève, à Hong Kong, Rio, New York, Toronto. Beaucoup de villes circulent dans ce roman et dans chaque ville il y a une vie. Quand j'ai eu terminé ce livre qui est le plus ambitieux, le plus long que j'aie écrit, je me suis rendu compte que, sans le vouloir, j'avais refait un peu les Mille et une nuits. Parce qu'une histoire annonce une autre histoire qui est indépendante et il y a toujours le même fil. Je n'ai pas voulu imiter les Mille et une nuits mais c'était la thématique qui s'est imposée à moi. C'est la même personne qui cherche toujours la fortune et qui poursuit cette fortune à travers... Dans les Mille et une nuits c'était plus mythologique et c'était aussi la quête du monde tel qu'il existait à l'époque, maintenant le monde existe d'une autre manière. Quelle est la vie à Hong Kong que le personnage connaît, quelle est la vie à New York ou à Toronto ou à Genève, ou à Milan? Dans chaque ville il y a une vie et c'est une vie différente et comment cette personne - et c'est ça aussi l'une des grandes préoccupations que j'ai et qui se déclare dans ce roman - comment la même personne peut vivre tant de villes et tant de cultures sans se perdre? J'ai découvert, après avoir terminé le livre, qu'il est un homme de passage, c'est un passager, il n'est à peu près rien, sauf qu'à chaque endroit il est là où il est entièrement. Et à la fin, il voit que sa vie est faite de toutes les villes, pas seulement d'une seule. Il retourne à la ville d'où il est parti, il a fait le tour du monde pour revenir à son point de départ et il finit par épouser, sans même le vouloir, quand il est sur le point d'attraper la personne qui lui a dérobé son argent, qui serait prête à le lui rendre, il la voit mais il ne veut pas la voir, il ne veut pas lui parler, il la laisse partir mais il va vers la fille de cet homme qu'il ne trouve pas jolie mais qu'il désire et aime et finit par épouser. C'était ça finalement sa fortune. C'est très ambigu.

V. \& I. - Tout en héritant de la fortune du père grâce au mariage?

N. Kattan - Elle, elle ne veut pas de son père, elle n'est pas en accord avec son père. Mais de toute manière, entre-temps, il est devenu millionnaire, il n'a pas besoin d'argent, il n'a plus besoin de cet argent-là, il a déjà fait sa fortune 
en la cherchant. C'est une réflexion aussi, pour quelqu'un qui, comme moi, a voyagé, a essayé de connaître les autres cultures, de dire qu'on ne se perd pas dans les cultures, on se retrouve. On ne se disperse pas dans l'échange on finit par s'y retrouver. Même si ce n'est pas l'Amérique que l'on découvre quand on part à l'aventure, on découvre une terre. Si ce n'est pas cette fortune-là, c'est une autre fortune qu'on découvre mais qui est une fortune. Mais enfin, c'est un roman picaresque, ce n'est pas un roman philosophique du tout. C'est un roman d'aventures, amusant. Mais c'est bien que tu sentes le fil des Mille et une nuits parce que j'ai écrit un roman qui est une autre mouture, un peu, des Mille et une nuits.

Je dois aussi ajouter pour les Mille et une nuits que j'ai fait dans mon dernier livre, le Désir et le pouvoir, un chapitre qui s'appelle «la Séduction» qui parle des Mille et une nuits et que j'ai relu entièrement en arabe, parfois je trouvais le livre un peu ennuyeux à la longue parce que c'est répétitif et que ce n'est pas un grande œuvre littéraire contrairement à ce qu'on pense, il est d'ailleurs méconnu dans la littérature arabe, mis à part, ne fait pas partie de la littérature arabe. Dans toute l'histoire de la littérature arabe on ne parle pas des Mille et une nuits, c'est un livre populaire de contes que l'Occident a découvert et que le monde arabe redécouvre parce que c'est un livre de lecture amusante, populaire, mais il a une signification plus grande que beaucoup de livres philosophiques ou d'essais.

V. \& I. - En parlant de ton dernier roman, je crois que tu viens de dire que ce serait beaucoup moins autobiographique ou en tout cas beaucoup moins relié à ta vie réelle que les autres?

N. Kattan - J'aimerais bien dire ça, mais je crois qu'il y a beaucoup quand même d'autobiographie. Je n'ai parlé d'aucune ville que je n'aie pas visitée et connue moi-même. L'argument narratif n'est pas personnel, ce n'est pas du tout moi, ce n'est pas voulu autobiographique, mais il y a des éléments autobiographiques évidents parce que ce sont des villes que j’ai connues, ce sont des personnes que j'ai connues mais que j'ai changées d'endroit et même, parfois, des femmes que j’ai rencontrées, dont j’ai pu connaître la vie. Ce n'est pas tout à fait imaginaire. Quand je décris par exemple Rio, ce n'est pas une ville imaginaire, c'est une ville que j'ai connue, que j'ai sentie de la même manière que Paris ou Londres ou d'autres villes.

V. \& I. - Ça ne m'étonne pas parce que tu as toujours un point de vue qui reste proche de celui du journaliste et toutes tes fictions donnent lieu à des références assez précises, pour les rues en tout cas de Montréal, je peux en témoigner, ou de Paris dans les Fruits arrachés, et pour la Fiancée promise, c'est la même chose.

J'aimerais maintenant en venir aux nouvelles. Est-ce que mon impression est juste ou en tout cas qu'est-ce qui t'en semble, je ne peux pas dire que j'ai eu le temps de toutes les relire, je viens surtout d'entreprendre la lecture du dernier recueil, la Reprise, et il me semble que le projet nouvelle dans ton cuvre est moins accompli que le projet romanesque, que cela correspond davantage à une écriture rapide, comme si la matière était moins travaillée? Est-ce que pour toi chacun des livres des nouvelles correspond à un projet précis, est-ce que le recueil est un recueil ou si c'est pour toi plus que cela: un 
livre, c'est-à-dire est-ce que le montage des nouvelles a une importance et alors tu pourrais peut-être prendre l'exemple du dernier recueil, pourquoi est-ce que ce recueil s'intitule la Reprise et que la nouvelle la Reprise on la trouve assez loin dans le livre, elle n'ouvre pas le texte? Pourquoi la première nouvelle les Mémoires ne me paraît pas la plus intéressante pour ouvrir le recueil... À quelle stratégie répond l'assemblage ou disons le rassemblement de ces textes?

N. Kattan - L'écriture des nouvelles, pour moi, ce n'est pas un projet, dans mon entreprise, moins travaillé que le roman. S'il donne cette impression-là, j'en suis responsable sans l'avoir voulu.

D'abord, pourquoi j'écris des nouvelles et pas toujours des romans? Je reviendrai peut-être après pour dire que j'ai écrit de nombreuses pièces de théâtre, surtout radiophoniques, et qui correspondent à peu près à la même démarche que les nouvelles, c'est une autre forme que les nouvelles. Ce que j'essaie de faire? À un certain moment, la vie telle que je la vois ne me semble pas se dérouler dans une durée mais dans un environnement et dans un état qui, pour moi, est l'état de mon humeur, de mon tempérament de ces annéeslà. Cet état-là me fait voir les personnages, les personnes et la vie autour de moi d'une manière découpée en mosaïque. C'est-à-dire que je ne vois pas les gens reliés entre eux, je les vois en tranches. La nouvelle me permet de découper dans le réel ces moments qui me prennent. Parfois, quand j'écris une nouvelle, ça me bouleverse moi-même parce que, ce que je dis, je ne m'attendais pas à le dire moi-même. Je suis pris par un de mes personnages qui est imaginaire en grande partie et qui finalement n'est qu'une expression d'un inconscient en moi. La Reprise c'est le cinquième recueil de nouvelles et c'est le seul recueil dont le titre est le titre d'une des nouvelles. Dans tous les autres, il n'y a pas de nouvelle qui corresponde au titre. Et c'est voulu. Il y a une thématique, si l'on veut, que je n'ai pas voulue quand je les écrivais. Heureusement, je n'ai pas de concept quand j'écris des nouvelles, c'est après que je vois. Une fois que le recueil est terminé, je vois comment il est disposé. Et je dois dire que je le dispose pas d'une manière conceptuelle mais d'une manière qui me semble artistiquement ou littérairement valable. Donc, c'est plus intuitif que voulu. Il faudra qu'il passe du temps pour que je puisse être moi-même l'analyste de ce que j'ai voulu faire, que j'ai fait, parce que j'écris en même temps des essais et des articles et je ne veux pas quand j'écris des nouvelles et des romans être l'analyste de ce que je fais parce que toute entreprise de fiction disparaît. Je suis donc complètement libre de toute entreprise pensée. Je ne pense pas, je sens ce que j'écris. Je pense d'une autre manière, autrement dit.

Dans chaque recueil, il y a un titre et ce titre-là correspond à ce que j'ai voulu. Je peux m'être trompé. Il y a quelqu'un qui a fait une analyse de cette thématique de l'eau, parce qu'il y en a beaucoup dans mes recueils de nouvelles. Dans le Désert et après c'est la Traversée, le Rivage, le Sable de l'île et la Reprise. Dans la Reprise, pourquoi je l'ai appelé ainsi? C'est que jusqu'à maintenant toutes mes nouvelles se terminaient assez mal et il y avait une sorte d'angoisse. Les lecteurs qui me connaissaient personnellement m'ont dit que je les trompe en quelque sorte parce que je n'ai pas l'air d'être ni triste, ni tragique, ni malheureux et que dans mes nouvelles il n'y a pas une 
histoire d'amour qui se termine bien, il n'y a rien qui marche, tout va mal; il y a une sorte de pessimisme. Mais moi, je ne peux pas refaire, je trouve que le monde autour de moi m'oblige à écrire ce que j'écris. C'est comme ça que je ressens le monde sans le vivre de cette manière-là et c'est ça qui ressort dans mes nouvelles. Dans la Reprise, je crois qu'il y a exactement ce mot, c'est-àdire la vie d'une manière assez fragile, faible mais persistante et réelle qui reprend le dessus.

V. \& I. - Mais en même temps, j'ai constaté que dans la Reprise, tes nouvelles se font plus près de l'essai qu'auparavant?

N. Kattan - Je ne sais pas si toutes sont comme ça mais il y a une observation qui se ramasse plus sur des personnages qui vivent des situations qui ne sont pas uniquement individuelles. C'est des situations aussi où la mémoire, où le vieillissement, où le rapport familial les dépassent. Et c'est pour ça qu'il y a une sorte de réflexion qui est non pas intellectuelle mais une réflexion inhérente à la nouvelle même sur ces questions-là.

V. \& I. - Ça me paraît plus accusé qu'auparavant?

N. Kattan - Peut-être. Je suis mal placé pour en juger.

V. \& I. - En particulier, celle qui s'intitule île où tu racontes l'histoire de deux amis, l'un qui retrouve l'autre au téléphone et qui se souvient de ce qu'il était. En fait c'est la description d'un paranoïaque qui veut écrire un grand livre, le livre final, total sur ce qu'est la littérature.

N. Kattan - En fait, c'est presque la description d'une histoire telle qu'elle m'est arrivée à moi. Ce personnage se retrouve dans une autre de mes nouvelles dans un précédent recueil, dans le même lieu, au Brésil, c'est une histoire tout à fait bouleversante qui m'est arrivée, telle qu'elle est décrite. Alors je ne peux même pas la juger parce qu'elle m'a tellement bouleversé que je n'ai fait que la transcrire telle que je l'ai vécue. Cet homme que je décris n'a vu littéralement personne en plein Rio pendant huit ans sauf moi, deux fois, et, chaque fois, cela a donné lieu à une de mes nouvelles. $C^{\prime}$ 'est quelqu'un qui est malade, nettement malade d'une maladie psychologique mais en même temps, quand je le retrouve, il est lumineux de pensée et toute notre vie commune d'étudiants à Paris - on était lié comme étudiants à Paris il y a donc trente quelques années - revient à la surface et lui redevient cet écrivain, il était un écrivain, le plus intelligent que j'aie connu...

\section{V. \& I. - C'est le Julio des Fruits arrachés.}

N. Kattan - Oui. Alors il revient dans plusieurs endroits parce que c'était quelqu'un à qui j'étais très lié et qu'il bouleverse l'idée que j'ai d'une vie rationnelle. Parce que la vie irrationnelle que j'ai vécue avec lui est irrationnelle, mais avec sa propre logique. Alors ça bouleverse beaucoup de choses en moi et je n'arrive pas à en sortir. Il faut que je l'écrive, ça. C'est vraiment pas pensé, c'est vécu tel que c'est. J'ai vu le manuscrit de cet homme-là qui est le grand livre le plus extraordinaire qu'on puisse écrire sur la littérature. Je ne peux pas l'expliquer... Cette nouvelle est vraiment pour me débarrasser de l'angoisse, du mystère d'une amitié qui dure, en dépit des années. J'arrive à Rio, je téléphone et il me répond, il ne répond à personne d'autre et la conversation reprend... 
V. \& I. - En terminant, il y a là quelque chose de contradictoire dans une entreprise dont le caractère autobiographique est plutôt affirmé, ce sont les points d'ombre, assez nombreux...

N. Kattan - Je crois que ces points d'ombre, dans les romans, les nouvelles et les pièces de théâtre expriment ce rapport à la fois riche, heureux mais difficile et ambigu entre les cultures, et les hommes, et surtout entre hommes et femmes. Et que si la vie se poursuit, c'est dans la difficulté. Il n'y a pas d'autres moyens pour la vie de se poursuivre sans que ce soit dans cette difficulté du dit et du non-dit. Et le non-dit parfois dit plus que le dit et c'est ça qui est pour moi l'écriture. C'est une sorte de secret qui a du mal à se révéler mais qui ne cherche qu'à se révéler, qui ne cherche qu'à se dire. Mais dès qu'il se dit, il est dénaturé, diffus et dissout. Il y a une sorte de disparition. La vie fait disparaître des secrets pour en engendrer d'autres. C'est ça qui fait la continuité de l'écriture.

On m'a dit souvent que j'ai choisi le non-dit ou le dit quotidien parce que ce n'est pas ma langue maternelle. Or, je ne crois pas que ce soit ça le problème. J'aurais pu écrire dans Adieu Babylone un discours beaucoup plus étoffé dans les images et les descriptions, mais ce qui a été écrit correspondait à un besoin. Ce n'est pas un choix conscient. Ce que je veux dire ne peut être dit que de cette manière-là. Ce n'est pas par manque ou incapacité. N'importe quel écrivain a des problèmes avec la langue, y compris moi-même, mais ce n'est pas parce que ce n'est pas ma langue maternelle... Je la considère maintenant comme ma langue d'écriture, et je suis, dans la mesure du possible, en possession de cette langue, comme n'importe quel autre écrivain. Mais c'est toujours une possession insuffisante, hasardeuse, incomplète et difficile.

V. \& I. - Même Goethe disait à quatre-vingts ans qu'il continuait d'apprendre l'allemand.

N. Kattan - Eh! oui... 